\title{
CULTURA, IDENTIDADE CRÍTICA E INTERVENÇÃO EM EDUCAÇÃO FÍSICA ESCOLAR
}

\author{
Diego Luz Moura \\ Universidade Gama Filho, Rio de Janeiro, Rio de Janeiro, Brasil \\ Antonio Jorge Gonçalves Soares \\ Universidade Federal do Rio de Janeiro, Rio de Janeiro, Rio de Janeiro, Brasil
}

\begin{abstract}
Resumo
Este artigo tem como objetivo analisar a produção crítica que aponta uma intervenção em Educação Física a partir do termo cultura. Realizamos uma análise de artigos em quatro periódicos no período de 1992 a 2004. A partir da análise, argumentamos que esta produção forneceu poucos elementos para a construção de propostas de intervenção. Apesar disso, concluímos que o movimento identitário gerado por tais propostas foi fundamental para a construção de uma "nova" Educação Física.
\end{abstract}

Palavras-chave: Cultura. Identidade. Educação Física Escolar.

\section{Introdução}

— ste artigo pretende apresentar os paradoxos da produção acadêmica da perspectiva crítica da Educação Física escolar. A perspectiva crítica da Educação Física se inicia na década de 1980, a partir de uma nova configuração no panorama político e acadêmico brasileiro. Tal perspectiva foi inspirada nas teorias críticas da educação que começaram a questionar o currículo tradicional (SILVA, 2007). Os críticos procuravam questionar a neutralidade da educação no processo histórico, social, político e econômico. Por vezes, denunciavam o esporte como ópio do povo e instrumento a serviço da ideologia da classe dominante. Essas teorias costumavam operar análises autodenominadas progressistas, inspiradas no marxismo para explicar finalidades sociopolíticas da educação (CAPARROZ, 1996). Podemos apontar que essa influência instalou novos objetivos para a Educação Física escolar. Em vez de o foco ser a aptidão física, o desenvolvimento esportivo ou a saúde como função dessa disciplina no currículo, a meta passou a ser a utilização desses temas de ensino para desvelar as artimanhas do sistema capitalista que também engendraria seus va- 
lores nesse espaço pedagógico.

A produção da perspectiva crítica encontrou no termo "cultura" sua marca para afastar-se da visão biológica que identificava essa disciplina no currículo escolar. Pode-se afirmar que a identidade tradicional dessa disciplina na escola sempre esteve atrelada à ideia de que o corpo deveria ser desenvolvido como uma máquina que deve funcionar bem do ponto de vista biológico, psicológico e moral. Desse modo, a Educação Física teria um caráter prático e utilitário ao funcionamento da instituição escolar. Em contrapartida, o termo cultura passou a representar uma ruptura com essa identidade funcionalista. Nesse espaço curricular, a ideia de cultura tornou-se uma espécie de adjetivação nos vários nomes que recebeu: cultura física, cultura de movimento e cultura corporal. De fato, cada uma dessas adjetivações foi criada por diferentes autores a partir de distintas motivações. Entretanto, elas representam uma tendência de novas perspectivas a partir do termo cultura.

Atualmente, os defensores dos modelos críticos enfatizam que o papel da Educação Física é socializar as novas gerações com a cultura corporal de forma crítica. Nesse sentido, a disciplina Educação Física deveria selecionar práticas e saberes da cultura corporal como conteúdos a serem ensinados, desnaturalizados e analisados a partir da perspectiva de classes, das relações de poder.

Sem dúvida, a principal marca da perspectiva crítica foi formular o conceito de cultura corporal como eixo que deveria guiar o processo de seleção dos conhecimentos e práticas a serem pedagogizados e problematizados nas aulas. Como a ideia de cultura corporal era ampla e incluía todo o fazer humano, os teóricos indicaram o que deveria ser considerado como elementos da cultura corporal: jogos, esportes, danças, lutas e ginásticas a partir de uma leitura crítica dos significados culturais que tais práticas possuem na sociedade capitalista.

Podemos afirmar que a perspectiva crítica da Educação Física fez parte de um processo de "luta de demarcação do campo" na década de 1980. Ao analisarmos a produção de 1992 a 2004, descreveremos a proximidade e a filiação da perspectiva crítica da Educação Física às teorias críticas da educação, e mostraremos que o debate na Educação Física apenas se apropriou da primeira fase ${ }^{1}$ das teorias críticas da educação no Brasil.

1-Consideramos como primeira fase o impulso inicial de realização de críticas e denúncias.

Pensar a Prática, Goiânia, v. 15, n. 4, p. 821-1113, out./dez. 2012 
Nosso argumento central é que esse movimento crítico e teórico, na realidade, apresentou poucos elementos para uma intervenção que transformasse os saberes e as práticas docentes.

As obras relacionadas à perspectiva cultural ganharam maior visibilidade a partir da publicação do livro Metodologia de ensino da Educação Física, de autoria de um grupo autointitulado Coletivo de Autores, em 1992. Esse livro ganhou repercussão na área porque difundia o debate crítico e procurava oferecer uma sistematização dos conhecimentos sobre a aula de Educação Física. Como já dito, uma das principais contribuições para a área foi o conceito de cultura corporal, que ganhou autonomia sobre o livro e sofreu novas apropriações em diferentes perspectivas. De qualquer modo, independentemente de suas matrizes pedagógicas e/ou teóricas, todas essas novas concepções "culturais" se aproximam da ideia de que as ciências humanas e as teorias da educação devem ser o seu fundamento.

\section{Metodologia}

Analisamos a produção da perspectiva crítica de 1992, ano de publicação do livro do Coletivo de Autores, até 2004, ano do levantamento da produção. A pesquisa se concentrou em quatro periódicos: Revista Motus Corporis, Revista Paulista de Educação Física, Revista Movimento e a Revista Brasileira de Ciências do Esporte. A escolha dos periódicos se deu pelo fato de serem aqueles que possuíam seu acervo digitalizado no momento do levantamento.

O processo de seleção dos artigos seguiu três fases: a) leitura dos resumos de todas as obras para identificar os artigos sobre a Educação Física escolar; b) leitura na íntegra dos artigos da temática Educação Física escolar vinculados à perspectiva cultural; c) análise dos artigos.

A partir da leitura dos resumos, verificamos um total de 167 artigos sobre Educação Física escolar. Ao realizar a leitura desses artigos na íntegra, encontramos 20 artigos na perspectiva cultural. Após a análise, identificamos três perspectivas teóricas: a perspectiva crítica, da mediação e a antropológica ${ }^{2}$. Neste artigo, analisamos apenas a perspectiva crítica.

Encontramos um total de sete artigos da perspectiva crítica. Durante a análise dos artigos, identificamos dois autores como principais 2-Discutimos a perspectiva antropológica em Moura e Lovisolo (2008). 
representantes desse movimento: Resende e Bracht. Por esse motivo, decidimos inserir mais duas obras ${ }^{3}$ como objetos de análise, ampliando, assim, o entendimento sobre a produção crítica nesse período.

\section{Resultados}

Os autores desta perspectiva se identificam com o movimento crítico por meio de três diferentes tipos de apropriações. A primeira se apropria do debate da pedagogia histórico-crítica no campo da educação. Resende (1994a; 1994b; 1995), Resende e Soares (1996) e Bracht (1996; 2006) são autores que apontam nesse sentido.

A segunda apropriação marca o debate produzido pela pedagogia crítico-superadora, que é uma proposta do próprio campo da Educação Física, que teve como principal inspiração a pedagogia históricocrítica. Dessa forma, Silveira e Pinto (2001) e Vieira (2000) procuram marcar o debate da perspectiva cultural dentro do campo da Educação Física.

A última apropriação está relacionada aos autores da escola de Frankfurt. Nos artigos analisados, apenas Oliveira (2001) se declara adepto da escola de Frankfurt. Entretanto, suas análises não dialogam profundamente com tais referenciais. A filiação à escola de Frankfurt parece apenas servir como uma marca identitária. Oliveira tampouco cita autores do debate da Educação Física brasileira, como Bracht e Kunz, que, supostamente, seriam reconhecidos como adeptos dos referenciais da escola de Frankfurt. A declaração de filiação à escola de Frankfurt em Oliveira se conforma mais como uma filiação normativa ou identitária do que como argumento baseado em categorias de análise radical do fenômeno estudado.

Os argumentos presentes nos textos analisados podem ser separados nos seguintes tipos: a) a crítica ao sistema capitalista; b) a "redefinição" do campo de conhecimento da Educação Física; c) as propostas para a intervenção em Educação Física escolar; d) a intelectualização da Educação Física escolar; e) a desnaturalização ou ruptura com as ciências biológicas.

3-Resende (1995) e Bracht (2005).

Pensar a Prática, Goiânia, v. 15, n. 4, p. 821-1113, out./dez. 2012 1079 
A crítica ao sistema capitalista

Nos artigos analisados, é possível identificar estreita vinculação com elementos do movimento crítico da década de 1980. Essa produção vai incidir em denúncias ao sistema capitalista, lançando seu olhar sobre o cotidiano da Educação Física para "encontrar" os mecanismos que estimulariam o sistema de opressão, alienação e reforço do sistema capitalista. Desta forma, a sociedade, a Educação Física, o sistema escolar e o professor são alvos de análise nos textos levantados.

$\mathrm{O}$ principal ponto que devemos destacar neste item diz respeito às análises macroestruturais que retratam uma relação mecânica de causa e efeito entre o esporte e a reprodução da sociedade. Para os autores analisados, a escola, o lazer e o esporte são fenômenos que reproduzem incondicionalmente as desigualdades da sociedade. Por possuir características como seleção e competição, a estrutura do esporte parece induzir a um tipo de análise que associa diretamente o esporte como um produto ou efeito do sistema econômico. Nesse tipo de argumentação, o esporte é visto como reflexo ou mecanismo de reprodução do capitalismo. Por essa razão, alguns dos autores imaginaram a construção de um novo esporte (KUNZ, 1994).

Não existem ressalvas, nos argumentos dos autores, sobre a ação alienante do esporte, da escola e das aulas de Educação Física. Esses elementos são vistos invariavelmente como uma influência negativa que reproduz e intensifica valores negativos. Falta aos autores a compreensão de que todo fenômeno social pode ser apropriado e re-significado de diferentes formas. $\mathrm{Na}$ opinião desses autores, a instituição escolar deveria ser entendida como um local de conscientização e de luta contra a neutralidade política.

Silveira e Pinto (2001, p. 140) criticam o sistema escolar, pois ele reforçaria valores negativos do sistema capitalista.

$\mathrm{Na}$ escola, a prática pela prática, por não questionar os valores implícitos, acaba reforçando a utilização do lazer como um processo de controle social, ideológico, compensatório ou utilitarista, com o reforço dos mitos e preconceitos impregnados na sociedade capitalista.

Muitos especialistas concordariam com a crítica à "prática pela prática”, que tornaria a Educação Física escolar esvaziada de signifi- 
cados pedagógicos. Entretanto, Silveira e Pinto (2001) constroem suas críticas a partir da leitura macrossocial dos aspectos políticos. A Educação Física deveria questionar os "valores implícitos". A especificidade pedagógica é esquecida em detrimento do enfrentamento ideológico.

De acordo com Silveira e Pinto (2001), a aula de Educação Física deve ser entendida como um instrumento de conscientização funcional à formação do espírito crítico. O lazer deve ser pedagogizado para fornecer elementos de luta contra a dominação e controle social. Essa concepção indica um caráter utilitário para as aulas de Educação Física e para a prática de lazer, que deve se pautar prioritariamente pela luta contra o sistema capitalista.

Resende (1995) afirma que o papel da escola no sistema capitalista é reproduzir os interesses de acumulação do capital. É óbvio que a lógica do capitalismo é a acumulação ilimitada do capital, mas objetivamente nenhum desses autores indica os mecanismos pelos quais a escola brasileira reproduz os interesses para acumulação do capital. Sob o ponto de vista da educação como bem econômico, no Brasil essa esfera é um obstáculo ao desenvolvimento do capital. A escola brasileira, com seu baixo nível de qualidade e com pouca capacidade para formar competências úteis ao mercado, tem sido um empecilho para o desenvolvimento da economia em nível coletivo e individual (GIAMBIAGI; VELOSO; HENRIQUES, 2009).

Oliveira (2001) foca sua crítica no esporte-educação. Para o autor, o esporte não educa para a autonomia.

A prática de esportes como meio educativo representa, invariavelmente, a reprodução das condições de classe na sociedade capitalista. Ora, esse fato significa dizer que o profissional de Educação Física ou fecha os olhos para esta realidade social, ou assume o discurso da neutralidade política. (OLIVEIRA, 2001, p. 15 , grifo nosso)

Oliveira (2001, p. 16) opera com uma linha radical de denúncia, tratando o esporte como uma estrutura que reproduz valores de uma sociedade de classes. Segundo ele, "não pode existir, no sentido afirmativo da formação humana, um esporte educacional. $\mathrm{O}$ esporte não educa, não forma. Antes ele deforma!". O principal argumento de Oliveira para justificar que o esporte não possui caráter educativo é que 
ele fortaleceria o sistema capitalista, sendo "um lócus privilegiado de sujeição à ordem social, assumindo os códigos sociais do modus vivendi capitalista" (OLIVEIRA, 2001, p. 11). Esse autor constrói um argumento tão normativo quanto os ideólogos do esporte, que o afirmam como um espaço educativo por excelência. Assim, temos nesse universo argumentativo, sem base empírica, apenas uma oposição ideológica que pouco serviu para entender o fenômeno em suas diferentes formas de apropriação.

$\mathrm{Na}$ concepção de Oliveira (2001), qualquer possibilidade de intervenção educativa que se utilizasse do conteúdo esporte esbarraria em alguns obstáculos "intransponíveis". Para sustentar esse argumento, fornece exemplos sobre o esporte profissional, que se reproduziria na escola e nas aulas de Educação Física. A generalização é o principal problema de sua argumentação:

Por isso mesmo o esporte é elitista, pois somente um pequeno grupo restrito às regras de cada modalidade esportiva pode praticá-lo.

O esporte é altamente codificado, o que nega qualquer possibilidade de participação efetivamente autônoma do educando.

O esporte é altamente hierarquizado, uma vez que a obediência cega às regras, aos juízes (ou ao professor) são condições básicas de sua prática. (OLIVEIRA, 2001, p.14-15)

As diferentes expressões artísticas, inclusive o esporte de alto rendimento, sejam de origem popular ou aristocrática, quando se tornam um campo, também se tornam altamente codificadas e elegem o que é excelência ou mediocridade. Normalmente, esses espaços sociais constroem hierarquias em diferentes níveis e critérios de participação. No entanto, isso não quer dizer que não possam ocorrer mudanças no interior desses campos.

Em suas conclusões, Oliveira (2001, p. 16) aponta que o esporte apenas poderia possuir função educativa se realizasse uma crítica radical aos interesses implícitos dessa prática na sociedade capitalista.

O esporte educacional talvez tenha o seu papel justamente na perspectiva da negação da sociedade capitalista mediante a análise crítica dos códigos e da estrutura do esporte, das implicações éticas da mídia esportiva que manipula dados e infor- 
mações na consciência popular, do discurso oficial que representa interesses bem delineados da classe hegemônica.

A argumentação de Oliveira obriga-o a ser contraditório. Em um primeiro momento, afirma que o esporte reproduz "invariavelmente" a sociedade de classes e, num segundo momento, afirma que o esporte pode ser apropriado para realizar uma crítica à sociedade capitalista. Afinal, na concepção de Oliveira, o esporte é veneno e antídoto. Por fazer parte do próprio campo da Educação Física, talvez não possa ter assumido, na época, uma perspectiva ao estilo dos teóricos críticos do esporte na linha da contracultura.

Sobre a apropriação do esporte, Stigger (2002) e Moura (2009) verificaram que tanto no campo esportivo quanto na escola o esporte pode ser apropriado de diferentes maneiras. Acreditar que os valores e características do esporte são transmitidos de maneira fixa é negar a dinamicidade da sociedade.

\section{A "redefinição" do campo de conhecimento da Educação Física}

Outro lugar comum é a necessidade de redefinição do campo de conhecimento da Educação Física escolar. Os autores retomam os argumentos sobre a singularidade, legitimidade, especificidade e função da Educação Física escolar.

No processo de redefinir o objeto específico da Educação Física, a argumentação dos autores vai incidir em três pontos: a) a necessidade de se definir a especificidade da área; b) a especificidade da Educação Física está no conceito de cultura; c) a proposta de cultura está ancorada na ideia de patrimônio, quando seleciona os conteúdos clássicos do esporte, do jogo, da ginástica, da dança e da luta.

Resende (1994b; 1995) retoma o debate que procurava definir se a Educação Física poderia ser conceituada como um componente curricular ou apenas uma atividade. Segundo o autor, a especificidade da Educação Física está em se afirmar como uma disciplina diferente das demais.

Bracht (1996) concorda em parte com os argumentos de Resende (1994b; 1995), pois aponta que algumas das dificuldades para a superação da suposta crise de identidade resultava, na época, em ver a Educação Física como uma disciplina com estatuto epistemológico próprio. Segundo Resende (1995), existe uma precipitação em impor à 
Educação Física um status de disciplina, na medida em que não possui elementos para tal.

O fato da educação veicular, através de um processo de intervenção pedagógica, um conjunto sistematizado de conhecimentos, habilidades e valores, não confere a ela o 'status' de disciplina, seja acadêmica ou curricular. Enquanto ela não dispuser dos estatutos necessários e admissíveis à sua legitimação enquanto área de conhecimento, julga-se precipitado esse mecanismo de imposição. (BRACHT, 1996, p. 133)

Ao analisar a "falta de legitimidade", Resende (1994b, p. 23) mostra duas direções distintas. Em primeiro lugar, as proposições pedagógicas não deram conta de legitimar a Educação Física no âmbito escolar. Em segundo lugar, "uma parcela de intelectuais envolvidos com a área tem procurado legitimar a Educação Física escolar tentando igualá-la com as demais disciplinas curriculares". Os argumentos de Resende (1994b) e de outros autores da Educação Física só confirmam a hipótese de Goodson (2008) de que determinadas disciplinas não entram no currículo escolar a partir da dinâmica do campo científico. É justamente o contrário: a constituição das disciplinas escolares nasce de pressões sociais.

Observemos que o termo cultura passa a demarcar a função da Educação Física no currículo escolar. Vejamos.

[...] a função da Educação Física é educar para compreender e transformar a realidade que nos cerca, a partir de sua especificidade que é a cultura de movimento humano. (SILVEIRA; PINTO, 2001, p. 139)

[...] Para a configuração do saber específico da Educação Física devemos recorrer ao conceito de cultura corporal de movimento. (BRACHT, 1996, p. 23)

A Educação Física se justifica na escola, já que não há outra prática pedagógica que se ocupe da dimensão cultural de que só a Educação Física trata, que é a cultura de movimento humano, expressa nos jogos, nas danças, nas lutas, nos esportes e nas ginásticas. (SILVEIRA; PINTO, 2001, p. 139) 
A explicação dos autores não esclarece o que se entende como cultura corporal do movimento. Afinal, se a escola deve transmitir o patrimônio cultural acumulado com significados para novas gerações no presente, qual seria a principal contribuição das teorias críticas no campo da Educação Física? A resposta parece ser óbvia: socializar o patrimônio cultural e lê-lo junto aos alunos com as lentes de uma pedagogia, sociologia ou história crítica. Como fazer isso? Lembremos que o esporte e as atividades corporais como campo de investigação sistemática nas ciências sociais são um fenômeno recente. Os indícios presentes nos discursos apontam para o fato de que a perspectiva crítica da Educação Física produziu novas discursividades no campo e, talvez, tenha também produzido experimentalismos pedagógicos que ainda devem ser avaliados.

As leituras da época e ainda hoje indicam que o fenômeno esportivo ou ginástico deve ser interpretado e pedagogizado em diálogo com os condicionantes estruturais do sistema capitalista. Entretanto, a proposta é socializar essa experiência com os alunos para que seus condicionantes sejam revelados aos olhos de todos, por meio da prática e da leitura crítica construída pelo professor. A aposta é que tal revelação poderá produzir novas práticas corporais ou mecanismos de resistência à opressão do capitalismo.

As propostas para a intervenção em Educação Física escolar

É possível perceber algumas tentativas de sistematizações ou estratégias metodológicas. No entendimento desses autores, a intervenção na perspectiva cultural só acontece quando se articula a Educação Física com a crítica à sociedade.

No entanto, trabalhar na Educação Física com o movimentar-se na perspectiva da cultura (cultura corporal de movimento) não basta para colocá-la no âmbito de uma concepção progressista de educação, mesmo porque o conceito de cultura pode ser definido em termos social e politicamente conservadores. É preciso, portanto, articular um conceito de cultura que se coadune com os pressupostos sócio-filosóficos da educação critica. (BRACHT, 1996, p. 24)

Portanto, as transformações dos sentidos conferidos aos valores e princípios implícitos e explícitos na cultura corporal e nas 
práticas corporais (ginástica, esporte, dança, artes, recreação e etc.) pressupõem um tipo de intervenção filosoficamente definida e metodologicamente coerente, numa perspectiva de democratização da sociedade, ou seja, da superação do modo de produção capitalista, da divisão social do trabalho, da competitividade discriminatória, da exacerbação do individualismo, etc. (RESENDE, 1994b, p. 24)

Os autores acabam por indicar como função da escola e da Educação Física a democratização da sociedade, por meio da luta contra o sistema capitalista. Dessa forma, "essas manifestações corporais, produzidas socialmente, precisam ser historicizadas e assimiladas criticamente, não só pela sociedade, mas também através da escola" (RESENDE, 1995, p. 132).

As propostas presentes nesses artigos não possuem sistematizações claramente definidas, mas apenas alguns princípios que se pretendem norteadores para intervenção. Os autores não indicam como se operacionaliza tais conhecimentos, apenas ressaltam a recusa da influência do esporte de rendimento e da promoção da saúde, e sublinham a necessidade da crítica. Não se poderia dar modelos de intervenção porque isso limitaria o processo criativo de intervenção e inovação pedagógica.

Segundo Bracht (1996), existe um mal-entendido entre os "professores da prática", que compreendem a intervenção na perspectiva cultural apenas como um discurso. Podemos perceber o esforço dos autores em apresentar um conceito de Educação Física. Entretanto, essa produção representa apenas orientações gerais sobre a intervenção. Independentemente do argumento de Bracht, construiu-se a representação da perspectiva cultural apenas como um movimento que forneceu uma gramática para afirmar uma nova identidade ao profissional de Educação Física na escola.

\section{A intelectualização da Educação Física escolar}

Outro ponto presente no debate é o que estamos nomeando como intelectualização da Educação Física escolar. Esse conceito se baseia na ideia de que o professor de Educação Física, para além dos conhecimentos específicos, deveria ser um consumidor crítico de bens culturais e ser engajado politicamente. 
Resende e Soares (1996) apontam que a aula de Educação Física deve possibilitar o desenvolvimento crítico da "cultura corporal homem-sociedade". Segundo os autores, os alunos devem vivenciar as possibilidades de atividades corporais e devem ser instigados a produzir análises e criações nesse espaço disciplinar. Para isso, o professor deve ser um conhecedor das especificidades da disciplina e um mediador cultural. Constataremos na citação a seguir a visão de que os alunos devem ser capacitados em alto nível de aprofundamento intelectual:

Neste contexto, são enriquecedoras as experiências de modificar as regras oficiais, instalações e equipamentos que identificam as atividades, os jogos esportivos, etc, de modo a favorecer o prazer e a participação integral do grupo; de analisar a importância das atividades corporais para o processo de formação continuada do homem; de analisar as implicações positivas e negativas da prática das atividades corporais em termos biológico, intelectual e sócio-cultural; de relacionar os conflitos e contradições emergentes durante as aulas com aquelas manifestadas na prática social, numa perspectiva crítica; de identificar e analisar os sentidos e os valores sociais, morais, éticos e estéticos subjacentes à cultura corporal, tendo como referência o contexto histórico da sociedade brasileira, dentre outros aspectos. (RESENDE e SOARES, 1996, p. 56, grifo nosso)

Silveira e Pinto (2001) defendem a inserção de aulas teóricas em Educação Física para que o aluno possa aderir à atividade física de maneira consciente, não se deixando levar por modismos.

A intelectualização é um movimento que procura (re)definir o papel do professor de Educação Física, de um mero instrutor de gestos esportivos para um intelectual que tenha competência para analisar a conjuntura política e cultural do corpo e do esporte, a fim de transformar essa competência em pedagogia. O professor deve ser um produtor e/ou consumidor cultural de alto nível a respeito das condições objetivas do magistério no Brasil.

Observemos que, apesar da positividade do valor, a intelectualização desse movimento se baseava, como já foi dito, na ruptura com a visão identificada como tradicional no campo e em um argumento de identidade para dentro e para fora do campo específico de embates. O 
que ocorria nesse contexto era uma disputa de poder entre posições teóricas distintas, próximo ao que Silva (2007) aponta quando se refere ao currículo como um espaço contestado de debates e disputas de poder.

Em busca da desnaturalização da Educação Física

De acordo com os autores, a Educação Física necessita buscar uma ruptura com os reducionismos que impedem a autonomia e legitimidade da área. Os autores entendem que a influência das ciências biológicas é um entrave que impossibilita o desenvolvimento da área. De acordo com Resende e Soares (1996, p. 55), "vislumbra-se, com essa proposta de especificidade e conhecimento, superar os reducionismos que têm caracterizado as concepções discutidas anteriormente".

$\mathrm{Na}$ esteira desse debate, Bracht afirma que o termo cultura "forçaria" uma redefinição.

Uma das razões para utilizar o termo cultura é a de que ele força uma redefinição da relação da Educação Física com a natureza e com seu conhecimento fundamentador. É preciso superar um certo "naturalismo" presente historicamente na nossa área. (2005, p. 99)

Bracht (2005) argumenta que a apropriação do termo cultura ganha importância na medida em que representa uma ruptura com a tradição biológica.

Cultura corporal, cultura de movimento ou cultura corporal de movimento? Em princípio qualquer um, desde que cultura, ou seja, desde que se coloque o peso maior neste conceito que, no meu entendimento, indica uma construção nova de nosso "objeto" é o de cultura. É ele que melhor expressa a ressignificação mais importante e a necessária desnaturalização do nosso objeto, que melhor reflete a sua contextualização sócio-histórica. (BRACHT, 2005, p. 97, grifo nosso)

Bracht não esclarece como um "peso maior" no conceito de cultura poderia construir um "novo objeto" para a área. No entanto, é um forte argumento para desnaturalizar a Educação Física. 
Neste contexto, a Educação Física na perspectiva da cultura corporal vem se apresentando como uma proposta necessária e imprescindível no sentido político-pedagógico. Ela deve ser pedagogicamente tratada no âmbito da escola de modo que a criança e o adolescente sejam intencionalmente levados à sua prática e à sua reflexão, superando qualquer tipo de natureza de reducionismos, sejam biologizantes, desportivizantes, psicopedagogizantes ou sociologizantes. (RESENDE, 1995, p. 132)

É importante termos claro que a definição do objeto da Educação Física está relacionada com a função ou papel social a ela atribuído e que define, em largos traços, o tipo de conhecimento buscado para sua fundamentação. Os termos atividade física, exercícios físicos, são fortemente marcados pela idéia de que o papel da Educação Física era contribuir para o desenvolvimento da aptidão física, pertencem claramente, no plano do conhecimento, ao arcabouço conceitual das disciplinas do âmbito da biologia, das ciências biológicas. (BRACHT, 1996, p. 23)

As citações de Bracht (1996) e Resende (1995) marcam a necessidade da desnaturalização da Educação Física. A desnaturalização é uma forma de estabelecer a diferença no jogo identitário com a tradição. Um dos pontos abordados por essa corrente é o de que qualquer manifestação corporal num passado imemorial seria Educação Física. Aqui fica evidente a luta desses especialistas pela redefinição do currículo para a Educação Física brasileira.

\section{Considerações finais}

A produção da perspectiva crítica opera como um movimento identitário que procura declarar a necessidade da (re)definição do campo de intervenção da Educação Física. A adoção do termo cultura foi a estratégia utilizada pelos autores para marcar a diferença entre a perspectiva cultural e a Educação Física tradicional. Os artigos realizaram apontamentos para a intervenção da Educação Física que, na maior parte das vezes, incluíam denúncias e críticas ao sistema capitalista, ponto comum entre os críticos e progressistas daquele período. Inspirados nas teorias críticas, os intelectuais da Educação Física criaram um material didático que serviu mais à instrumentalização de um discurso crítico para luta no interior do campo do que à produção 
de modelos pedagógicos que re-significassem o papel da Educação Física no interior da escola brasileira.

Por outro lado, representa as intenções e apontamentos de um momento histórico, o que de modo algum invalida o esforço dos autores em construir uma "nova" Educação Física em processo. Acreditamos que as experiências que vêm se construindo em distintas realidades escolares devem se tornar objeto de investigação, a fim de que possamos compreender os efeitos desse debate na construção de uma Educação Física que possa dar conta da tão proclamada formação integral do indivíduo.

\title{
Culture, critical identity and teaching school Physical Education
}

\begin{abstract}
The purpose of this article is to analyze the critical production which claims an intervention in school physical education from the culture term. It brings an analysis of works published in four academic journals in the period from 1992 to 2004 . From this analysis we argue that this production provided little evidence for the construction of intervention proposals, but was an important identity movement for building a "new" physical education.
\end{abstract}

Keywords: Culture. Identity. School Physical Education.

\section{Cultura, identidad y crítica de intervención en la escuela de Educación Física}

\section{Resumen}

En este artículo se pretende analizar los puntos críticos de producción a una intervención en educación física de la cultura plazo. Se realizó un análisis de los artículos en cuatro revistas de 1992 a 2004. De este análisis se argumenta que esta producción ha proporcionado pocas pruebas para la construcción de la intervención propuesta. Sin embargo, llegamos a la conclusión de que el movimiento de $\mathrm{La}$ identidad generada por estas propuestas fue fundamental em la construción de uma "nueva"educación física.

Palabras clave: Cultura. Identidad. Educación Física.

\section{Referências}

BRACHT, V. Educação física no $1^{\circ}$ grau: conhecimento e especificidade. Revista Paulista de Educação Física, São Paulo, 1996.

. Cultura corporal, cultura de movimento ou cultura corporal de movimento? In: SOUZA JUNIOR, M. Educação física escolar: teoria e política curricular, saberes escolares e proposta pedagógica. Recife: Edupe, 2005. 
CAPARROZ, F. E. A educação física enquanto componente curricular: entre a educação física na escola e a educação física da escola. 1996. (Dissertação de mestrado), Pontifícia Universidade Católica de São Paulo, 1996.

COLETIVO DE AUTORES. Metodologia de ensino da educação física. São Paulo: Cortez, 1992.

GIAMBIAGI, F; VELOSO, F; HENRIQUES, R. (Org.) Educação básica no Brasil: construindo um país do futuro. São Paulo: Campus, 2009.

GOODSON, I. F. Currículo: Teoria e história. 8. ed. Petrópolis: Vozes, 2008.

KUNZ, E. A transformação didático-pedagógica do esporte. Ijuí: Unijuí, 1994.

MOURA, D. L. Cultura e educação física: uma análise etnográfica de duas propostas pedagógicas. 2009. (Dissertação de mestrado), Universidade Gama Filho, Rio de Janeiro, 2009.

; LOVISOLO, H. R. Antropologia, cultura e Educação Física escolar. Revista Brasileira de Ciências do Esporte, Campinas, v. 29, n. 3, p. 137-153, maio 2008 .

OLIVEIRA, M. A. T. Esporte-educação: convivência ou ambigüidade. Revista Motus Corporis, Rio de Janeiro, 2001.

RESENDE, H. G. Princípios gerais da ação didático-pedagógica para a avaliação do ensino-aprendizagem em educação física escolar. Revista Motus Corporis, Rio de Janeiro, 1994a.

. Reflexões sobre algumas contradições da educação física no âmbito da escola pública e alguns caminhos didáticos pedagógicos na perspectiva da cultura corporal. Revista Movimento, Rio Grande do sul, 1994b.

. Subsídios para uma pedagogia da educação física escolar na perspectiva da cultura corporal. In: VOTRE, S. J; COSTA, V. L. M. (Org.). Cultura, atividade corporal e esporte. Rio de Janeiro: Gama Filho, 1995. 
RESENDE, H. G; SOARES, A. J. G. Conhecimento e especificidade da educação física escolar na perspectiva da cultura corporal. Revista Paulista de Educação Física, São Paulo, 1996.

SILVA, T. T. Documentos de identidade: uma introdução às teorias do currículo. 2. ed. Belo Horizonte: Autêntica, 2007.

SILVEIRA, G. C. F; PINTO, J. F. Educação física na perspectiva da cultura corporal: uma proposta pedagógica. Revista Brasileira de Ciências do Esporte, São Paulo, 2001.

STIGGER, M. P. Lazer, esporte e estilos de vida. São Paulo: Autores associados, 2002.

VIEIRA, E. M. Educação física e a cultura corporal: as orientações didático-metodológicas em questão. Revista Brasileira de Ciências do Esporte, São Paulo, 2000.

Recebido em: 16/11/2011

Revisado em: 05/03/2012

Aprovado em: 15/06/2012

Endereço para correspondência

Diego Luz Moura

lightdiego@yahoo.com.br

Centro Universitário da Cidade.

Rua Florianópolis 1.296

Praça Seca

21321-050 - Rio de Janeiro, RJ - Brasil 